\title{
Design of a Safety Accessory against Fire in Automobile
}

\author{
Baltha Manoj Kumar', A. Pradeep Reddy², K. Sai Kumar ${ }^{3}$ \\ ${ }^{1}$ Department of Mechanical Engineering, Vidya Jyothi Institute of Technology, Hyderabad, Technology State, India
}

\begin{abstract}
In India, number of accidents occur in our day to day life like fire accidents, road accidents etc., which occur due to negligence. During summer most of the accidents are due to fire because of overheating of the engine, lubricants, coolants and other parts that are made of thermoplastic materials in the area of the engine where heat is produced in the vehicle. This leads to burning of engine and blasts the complete vehicle which also leads to huge human and economical loss. Understanding the various issues regarding the mobility equipment, "DESIGN OF A SAFETY ACCESSORY AGAINST FIRE IN AUTOMOBILE" is introduced in order to save people from the fire, high pressure fire extinguisher is placed in parallel to the engine which is activated with the help of compression springs, so that it comes into play when the engine is overheated. This will be an asset for the automobile users, which becomes a helping hand for the people from fire accidents and hence saving their lives and property.
\end{abstract}

Keywords: Engine, Working principle of fire extinguisher, Melting temperatures, springs (INCONEL 718)

\section{Introduction}

\subsection{Design Parameters}

\section{1 .1.Heat engine}

Heat engine is a device which produces heat energy by burning fuel, which is converted to mechanical energy.

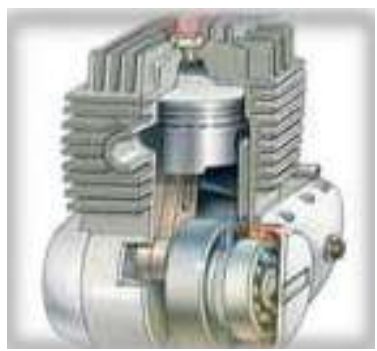

Figure 1.1.1: Heat engine

\subsubsection{Conditions of engine}

Normal temperature conditions of engine ranges from 195 to 220 degree Fahrenheit. There will be no threat to the engine, until it reaches the appropriate temperature. The fire usually develops in three states:

\subsection{2 (a).Beginning or incipient stage :}

In the incipient stage of an accidental fire, smoldering combustion occurs with temperatures often reaching $400^{\circ} \mathrm{F}$. Depending on the vintage of the vehicle, this stage can last up to 15 minutes. A fire accelerated by gasoline or other flammable liquid will progress through this stage much faster. The best opportunity to determine the fire's origin and cause, is at this point, assuming that the fire can be stopped.

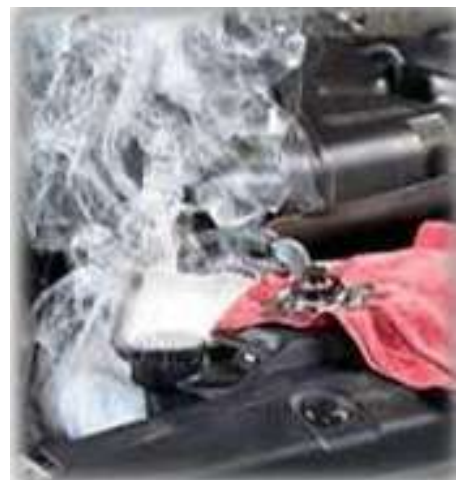

Figure 1.1.2(a): Gases coming out from the engine in Incipient stage

\subsection{2(b) . Burning stage}

The free burning stage sees a rapid rise in temperature to $1700^{\circ} \mathrm{F}$ or more. This sudden rise in temperature is due to the thermoplastic materials around the engine. Thermoplastic melting temperatures are approximately $340^{\circ} \mathrm{F}$ and up. Within 45 to 60 minutes, most cars burn completely, without any accelerants added to assist.

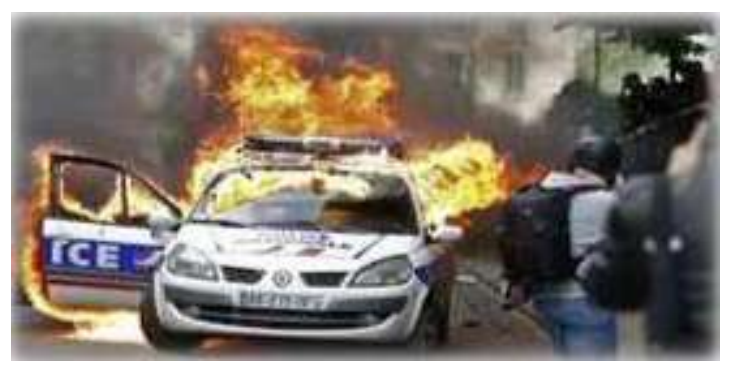

Figure 1.1.2(b): Burning stage

1.1.2. (c). Smoldering stage

Smoldering is the final stage, occurring after most combustibles have been consumed. Smoldering combustion may continue more than 90 minutes. 


\section{International Journal of Science and Research (IJSR) \\ ISSN (Online): 2319-7064}

Index Copernicus Value (2016): 79.57 | Impact Factor (2015): 6.391

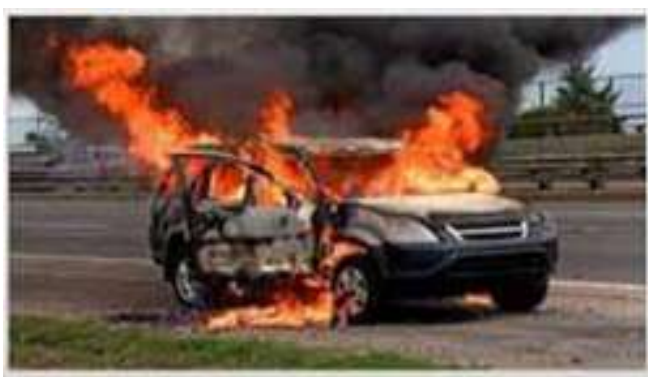

Figure1.1.2(c): Complete burning of vehicle in smoldering stage

\subsection{Fire Extinguisher}

A fire extinguisher is an active fire protection device used to extinguish or Control small fires, often in emergency situations.

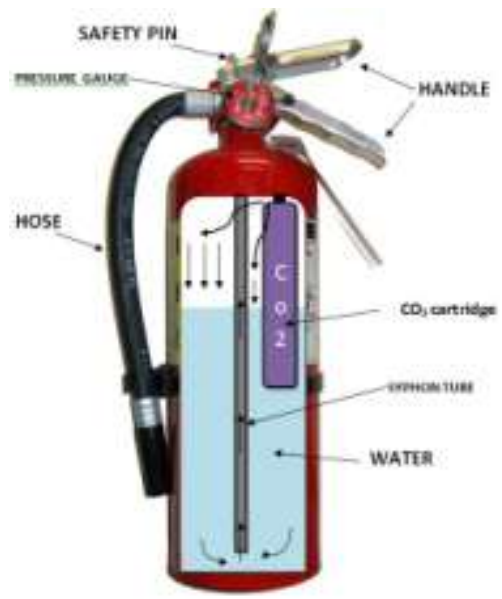

Figure: Fire Extinguisher

\subsubsection{Types of fire extinguishers}

The fire extinguishers are classified according to their purpose:

CLASS-A: (SOLIDS such as paper, wood, plastic, etc.,) CLASS-B: (FLAMMABLE LIQUIDS such as paraffin, petrol, oil, etc.,)

CLASS-C: (FLAMMABLE GASES such as propane, butane, methane, etc.,) CLASS-D: (METALS such as aluminum, magnesium, titanium, etc.,)

CLASS-E: (Fires involving Electrical Apparatus)

CLASS -F: (Cooking OIL \& FAT, etc.,)

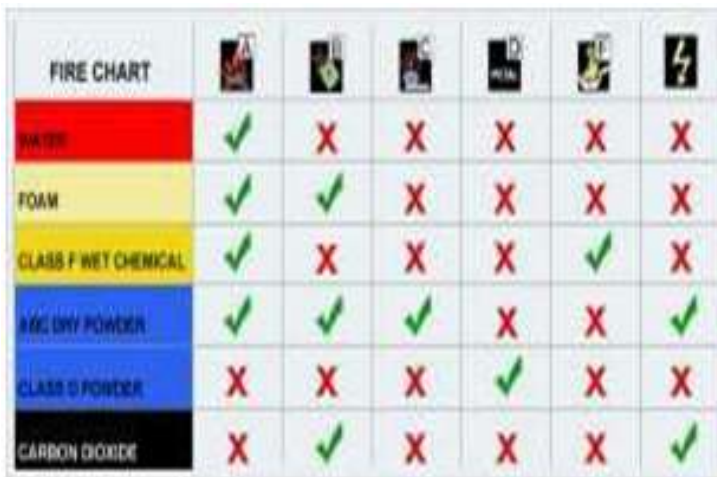

Figure 1.2.1: various types of fire extinguishers and their applications

\subsection{Spring}

A spring is an elastic object used to store mechanical energy.Springs are usually made out of spring steel. There are a large number of spring designs; in everyday usage the term often refers to coil springs.

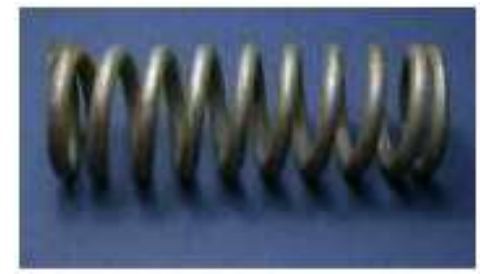

Figure 1.3: heavy-duty helical spring designed for compression and tension

The force in the compression spring can be calculated by using Hooke's Law

$$
F=k\left(L_{\text {free }}-L_{\text {def }}\right)
$$

Where,

$\mathrm{L}$ free $=$ Spring Free length

$\mathrm{L}$ def $=$ Spring length when Deformed $\mathrm{k}=$ Spring constant

\section{Main Discussion}

\subsection{Idea of introducing the design}

- When the engine is in normal conditions the heat produced in the engine does not cause any threat to the human life.

- But as the engine is in working condition it gets heated up beyond the normal conditions i.e., above 220 degrees Fahrenheit.

- In these conditions the coolants, lubricants, can cool the engine up to a certain stage.

- But as it is still in working condition a sudden increase in temperature in the engine leads to the burning of coolants, lubricants also, which can increase the temperature suddenly.

- In those conditions we can't stop the engine from burning .

- As we can't stop an engine from burning, a modification is done in order to prevent it.

- Therefore this design has been introduced.

\subsection{Design Parameters}

Table: Shows the parameters with suitable materials which is required for the design

\begin{tabular}{|c|c|c|c|c|}
\hline s/no & Component & Material & $\begin{array}{c}\text { Melting } \\
\text { point }{ }^{\circ} \mathrm{C}\end{array}$ & $\begin{array}{c}\text { Melting } \\
\text { point }{ }^{\circ} \mathrm{F}\end{array}$ \\
\hline 1 & Engine & Aluminum alloys & 660.3 & 1220.5 \\
\hline 2 & Spring & $\begin{array}{c}\text { High temperature } \\
\text { alloy (INCONEL } \\
718)\end{array}$ & 800 & 1472 \\
\hline 3 & $\begin{array}{c}\text { Fire Extinguisher } \\
\text { Cylinder }\end{array}$ & Low alloy steel & 1480 & 2500 \\
\hline 4 & $\begin{array}{c}\text { Fire Extinguisher } \\
\text { Powder }\end{array}$ & $\begin{array}{c}\text { Special powders } \\
\text { (M28/L2) (or) }\end{array}$ & - & - \\
\hline
\end{tabular}

Volume 6 Issue 12, December 2017 


\section{International Journal of Science and Research (IJSR)}

ISSN (Online): 2319-7064

Index Copernicus Value (2016): 79.57 | Impact Factor (2015): 6.391

\begin{tabular}{|c|c|c|c|c|} 
& (CLASS D) & co2 & & \\
\hline 5 & wire & Tin & 232 & 439 \\
\hline 6 & Rod & Cast iron & 1088 & 1990.4 \\
\hline
\end{tabular}

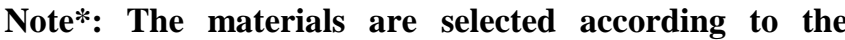
design of the engine in the vehicle.

\subsection{Working procedure for arrangement of design}

The water is half filled in the fire extinguisher cylinder which is made of low alloy steels whose melting temperature is about $2500^{\circ} \mathrm{F}$.

- At the top of the cylinder cap, a hole is made.

- Then a lock is made in such a way that the powder which is in the box is attached to the lock and it is inserted in the cylinder.

- Then a cylinder is placed parallel to the engine casing as shown in fig.2.3.

- Then one end of the four springs (High temperature alloy steels) whose melting point is above the burning temperature (around $1100^{\circ} \mathrm{F}$ ) is attached to the engine casing by a welding process at the corners of the engine block in the form of a square as shown in fig.2.3 .

- Then the four springs are attached together by placing the plate on the springs as shown in fig.2.3

- Then a tin rod is placed whose melting temperature should be in the range of burning temperature (i.e. below $500^{\circ} \mathrm{F}$ ) of the engine and whose one end is welded to the plate.

- Then the springs are forcefully pressed towards the engine casing and the other end of the rod is welded to the engine casing.

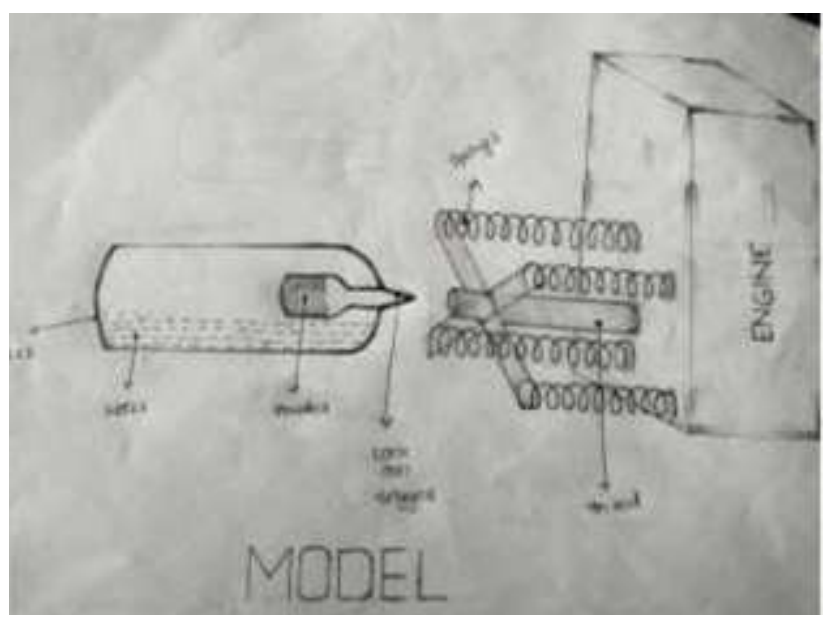

Figure 2.3: Schematic sketch of design of safety accessory against fire in an automobile.

\subsection{Working procedure of the design}

- When the engine is in the uncontrolled stage of burning, this design comes into play.

- When the engine is over heated the Tin rod, which is welded to the engine casing after being compressed, gets melted gradually.

- As the engine reaches to burning temperature (between 400 to $1700^{\circ} \mathrm{F}$ ) the rod melts completely and the springs which are compressed are released.

- Then the plate hit the lock which is inserted into the cylinder. As a result the powder in the box gets mixed with the water in the cylinder and thus forms the high pressured foam.

- Then immediately the highly pressured foam which is formed in the cylinder forcefully comes out and splash on the engine casing.

- Therefore the heat which is produced in the engine cools to normal temperature.

- The working principle of the fire extinguisher is that it controls the fire or puts off the fire.

- Thus the engine cools down and prevents from blasting of vehicle and therefore saves lives.

\section{Future Scope}

The current project can be further modified by using the sensors, and can be made with an automatic programming and can also be implemented not only in automobiles but also in all the heat producing machines or the elements.

\section{Conclusion}

Therefore we finally conclude that this Design of a safety accessory against fire in Automobile helps in preventing the fire accidents which can save lives of people and economical problems.

\section{References}

[1] "Aluminum alloy castings", by J. Gilbert Kaufman \& L. Rooy

[2] (http://www.sciencedirect.com/science/article/pii/S03797 11206000968) - Fire Safety journal by Zhigang Liu .

[3] Olson, David L., ed. ASM handbook: welding, brazing, and soldering. Vol. 6. Asm Intl, 1993.

[4] (https://books.google.co.in/books?isbn=3 5407381260) heat resistance material for springs, page 241, by Y.Yamada.

[5] Hird, D., "Dry powder extinguishing agents," Fire Research Note 210, Fire Research Station (1955). 